\title{
A Prospective Study of Inside out Transobturator Tape for The Treatment of Female Stress Urinary Incontinence - our Institutional Experience.
}

\author{
A R Balaji, Arun Kumar Sengottaiyan, Thiruvarul P V, Arunkumar P
}

\begin{abstract}
:
Introduction: Stress urinary incontinence is defined as involuntary leakage of urine on effort or exertion,or sneezing or coughing in the absence of bladder contraction. Modified transobturator (inside out) approach was described to improve the intraoperative safety profile of the obturator approach. The risk of lower urinary tract injury or other visceral injury is negligible with this approach.

Materials And Methods: A prospective study conducted between January 2015 to December 2016 in Government Stanley medical college and hospital, Chennai.including patients in the age group between twenty five and eighty five years and patients with Clinical as well as urodynamic diagnosis of stress urinary incontinence and with Positive pad test, stress test

Results: A total of 25 patients with Stress urinary incontinence where admitted in the present study. 23 patients in this study underwent vaginal delivery and 2 patients had undergone caesarean section. . 21 patients were very much satisfied with the procedure and 4 patients were satisfied with the procedure. The mean peak flow rate during the follow up was $26.65 \pm 2.12$, the mean post void residual urine during the follow up was 15.23 +6.01 .

Conclusion: On conclusion, the inside-out transobturator technique is simple, quick, and safe. It allows the accurate passage of the tape with minimal dissection, protection of the urethra and avoiding the pelvis. There have been no reported urethra or bladder injuries and no bowel or neurological complications. Post-operative continence rates are similar to the transvaginal tape procedure on short-term follow -up. In the future more randomized studies are necessary comparing the various midurethral slings and to further establish efficacy and safety of inside out transobturator vaginal tape.
\end{abstract}

Keywords: Stress urinary incontinence, transobturator (inside out) approach, transobturator vaginal tape

\section{Introduction}

Stress urinary incontinence is defined as involuntary leakage of urine on effort or exertion,or sneezing or coughing ${ }^{1}$ in the absence of bladder contraction. stress urinary incontinence is extremely bothersome and can lead to significant interference in the quality of life in the female population. Stress urinary incontinence affects upto $25 \%$ of women in India ${ }^{2}$.women have a $4 \%$ risk of needing Stress incontinence surgery during their lifetime with nearly $1 / 3$ of surgeries performed due to recurrence. The tension free vaginal tape procedure described by ulmsten has revolutionized the treatement of female Stress urinary incontinence.This procedure had high cure rate when compared to burch colposuspension. While this tapes have proved their long term efficacy,their insertion via an ascending or desending retropubic approach has been associated with number of intraoperative complications. The transobturator approach was first described by delorme in 2001 for placement of midurethral vaginal tape with the objective of avoiding retropubic area.It consists of insertion of the tape through a skin incision in the thigh into the obturator foramen towards the urethra.cadaveric dissections by various authors have proved this procedure is safer but complications like lower urinary tract injuries,vaginal tears and groin haematoma have been noted ${ }^{3}$.In 2003 a modified transobturator (inside out) approach was described to improve the intraoperative safety profile of the obturator approach.In this inside out transobturator method,the needle serially passes through the infra-urethra area,the obturator foramen,and the inguinal area.The risk of lower urinary tract injury or other visceral injury is negligible with this approach.

\footnotetext{
Aims And Objectives

1) To evaluate the efficacy of inside out transobturator tape in the treatment of female Stress urinary incontinence.

2) To determine the influence of inside out transobturator tape on objective and subjective cure rate and quality of life in patients with Stress urinary incontinence.

3) To asses the post operative complications and thus the safety of this procedure.
} 


\section{Materials And Methods}

A prospective study conducted between January 2015 to December 2016 in Government Stanley medical college and hospital, Chennai.

\section{Inclusion criteria :}

1) Patients in the age group between twenty five and eighty five years

2) Clinical as well as urodynamic diagnosis of stress urinary incontinence

3) Positive pad test, stress test

\section{Exclusion criteria :}

1) Detrusor overactivity or impaired bladder contractility

2) Post void residual urine $100 \mathrm{ml}$ or greater.

3) Pregnancy

4) Neurological pathology

5) Active urinary or vaginal infectionnts

\section{Methodology :}

A total of 25 patients with stress urinary incontinence in government Stanley hospital during the period November 2010 to January 2013 were asked to participate in this prospective study. All the women underwent a standardized preoperative evaluation including detailed incontinence history regarding duration and severity of stress urinary incontinence. All the patients underwent pelvic examination, a stress - test in upright position and a short term pad test. Urodynamic tests such as pressure flow study was performed in all patients for diagnosis of stress urinary incontinence and discrimination from urge incontinence. Urodynamic evaluation was done using laborie and medical measurement system urodynamic device. A Sterile 8 french dual channel cystometry catheter was placed into the urethra and a rectal catheter with $5 \mathrm{ml}$ balloon was placed into the rectum. The urinary bladder was filled with saline solution at the rate of $50 \mathrm{ml} / \mathrm{min}$ and the patient was asked to cough after each $100 \mathrm{ml}$ filling. Urinary incontinence occurring in this time was detected and the diagnosis of stress incontinence was made. Abdominal leak point pressure was measured in all patients and recorded. All patients were administered parentral first generation cephalosporin preoperatively for antibacterial prophylaxis. The inside out transobturator procedure was performed as described by leval. All patients were administered regional anaesthesia. Cystoscopy was performed to evaluate the bladder and urethra after the procedure. The duration of the procedure, cystoscopy and any additional operations, if performed, were recorded. All patients were monitored with the foley catheter for bladder drainage for 48 hours. Postoperative follow up was done at 6 weeks, here and six months. The objective cure was evaluated with a negative stress -test and 24-hour pad test. The subjective cure was also evaluated based on satisfaction of the patient with the procedur

\section{Results}

\section{Age Distribution}

\begin{tabular}{|l|l|l|}
\hline Age in years & Number of patients & Percentage of total \\
\hline $21-30$ & 1 & $4 \%$ \\
\hline $30-60$ & 11 & $44 \%$ \\
\hline $41-50$ & 8 & $32 \%$ \\
\hline$>50$ & 5 & $20 \%$ \\
\hline
\end{tabular}

A total of 25 patients with Stress urinary incontinence where admitted in the present study.The average age of the patient was $42.08+8.49$ years.

\section{Parity}

The mean parity of the patients with stress urinary incontinence was $2,52+0.77$ (mean+SD). The data collected indicated that the women with 2 children had more stress urinary incontinence 


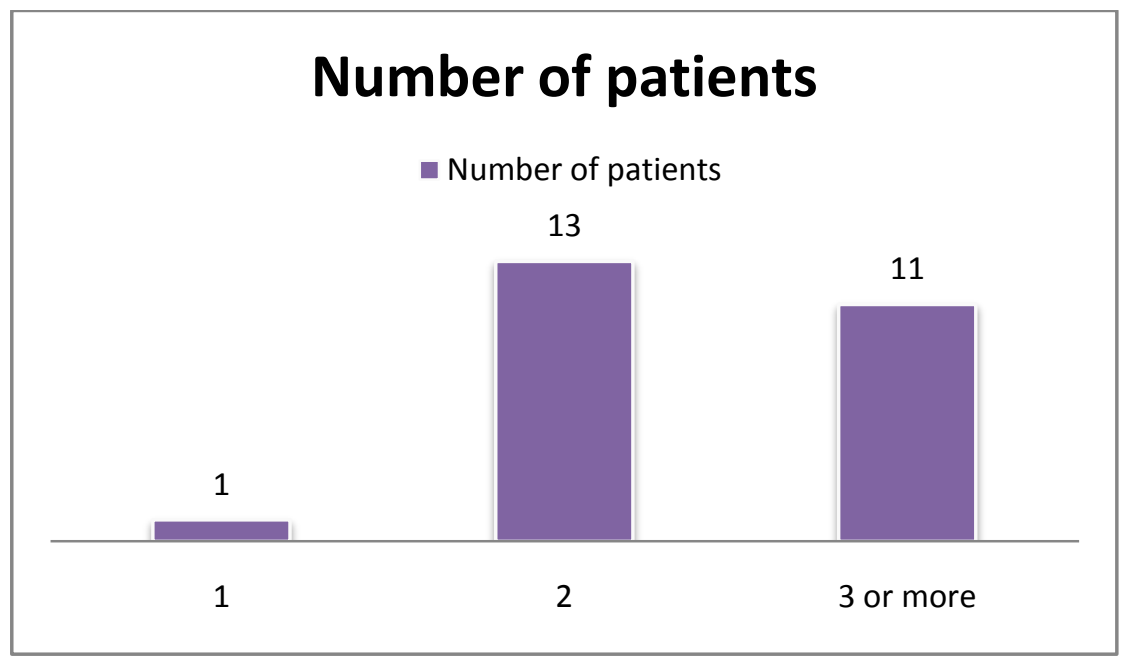

Menopousal Status

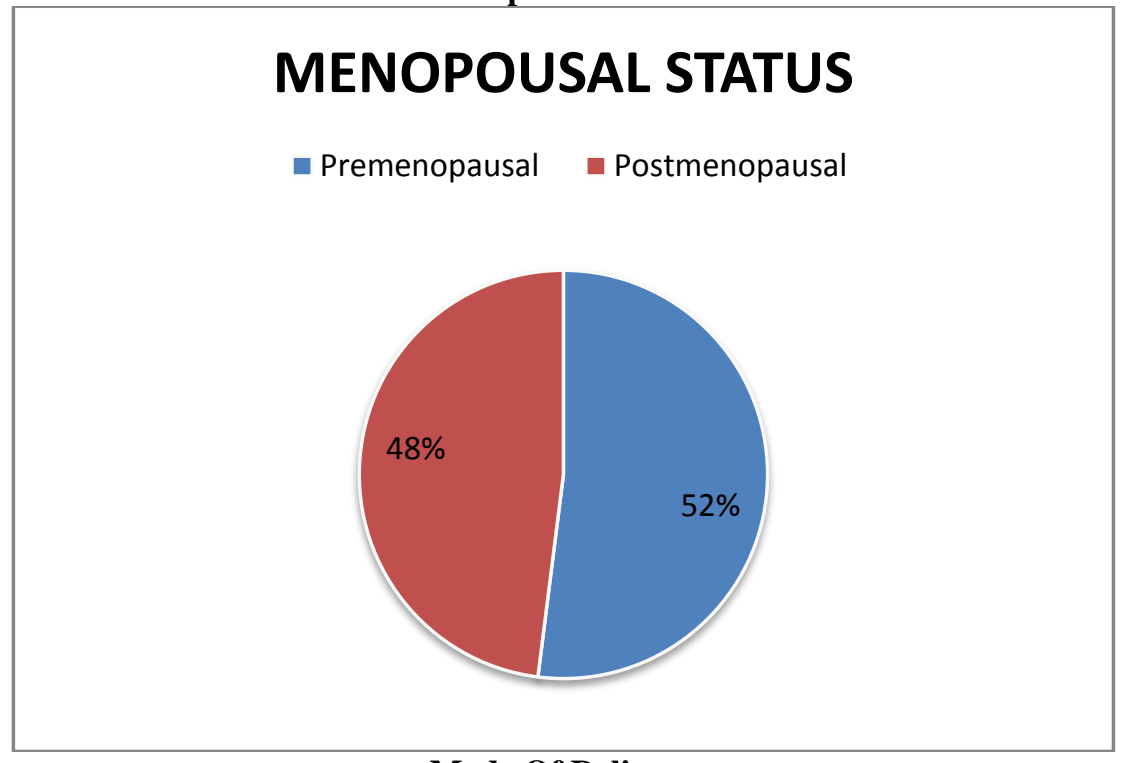

Mode Of Delivery

23 patients in this study underwent vaginal delivery and 2 patients had undergone caesarean section. Women who have had vaginal deliveries were found to have a higher association with stress urinary incontinence

\section{mode of delivery}

- Vaginal delivery $\quad$ Ceseraen section

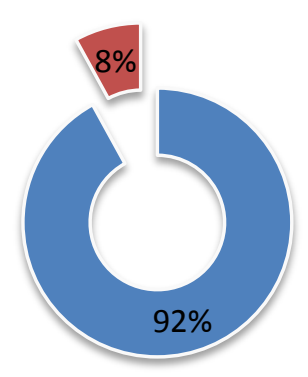


Previous pelvic surgeries :

\begin{tabular}{|l|l|}
\hline Prior pelvic surgery & Number of patients \\
\hline Abdominal hysterectomy & 3 \\
\hline Vaginal hysterectomy & 2 \\
\hline Caesarean section & 2 \\
\hline
\end{tabular}

Preop clinical parameters:

\begin{tabular}{|l|l|}
\hline Preop clinical parameters & Mean + S.D \\
\hline Symptom duration (years) & $4.56 \pm 1.75$ \\
\hline SUI Grade (range 1-3) & $2.24+0.52$ \\
\hline
\end{tabular}

Preoperative urodynamic parameters:

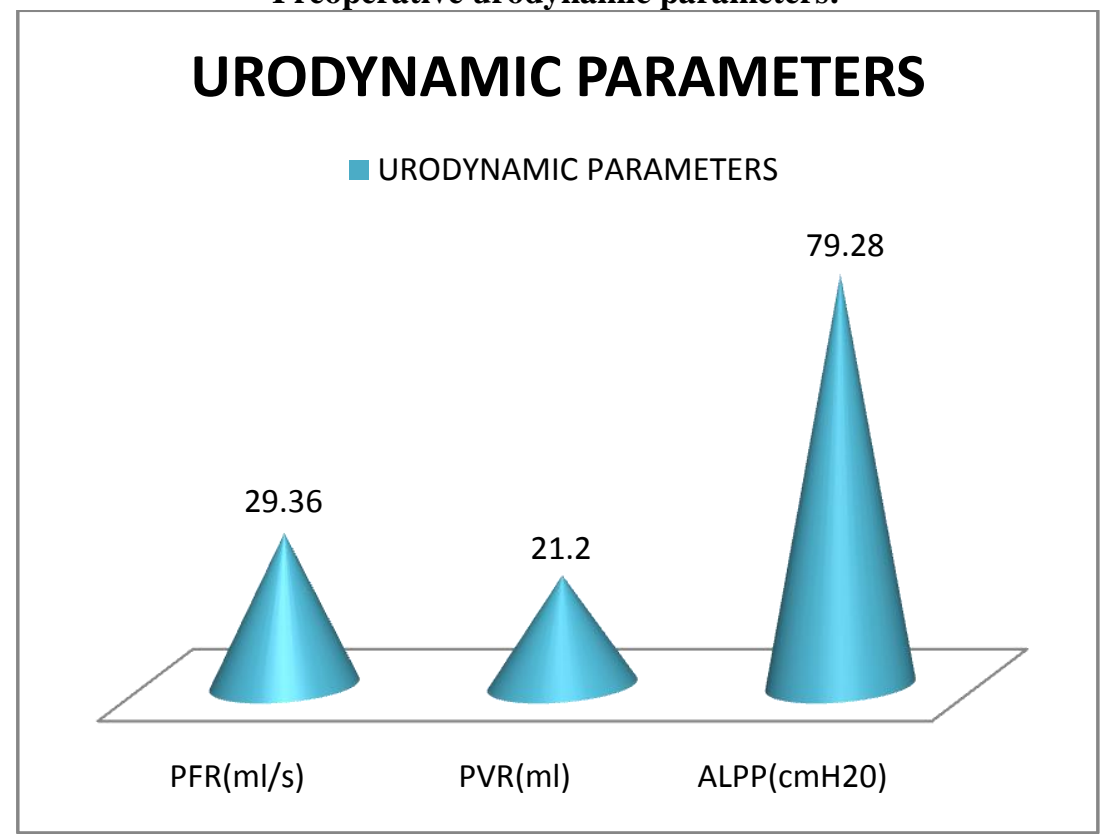

Postoperative complication:

\begin{tabular}{|l|l|}
\hline Complication & Number of patients (\%) \\
\hline Groin pain & $3(12 \%)$ \\
\hline Retention & $1(4 \%)$ \\
\hline Urgency & $1(4 \%)$ \\
\hline Hematoma & $1(4 \%)$ \\
\hline
\end{tabular}

\section{POSTOPERATIVE COMPLICATIONS}

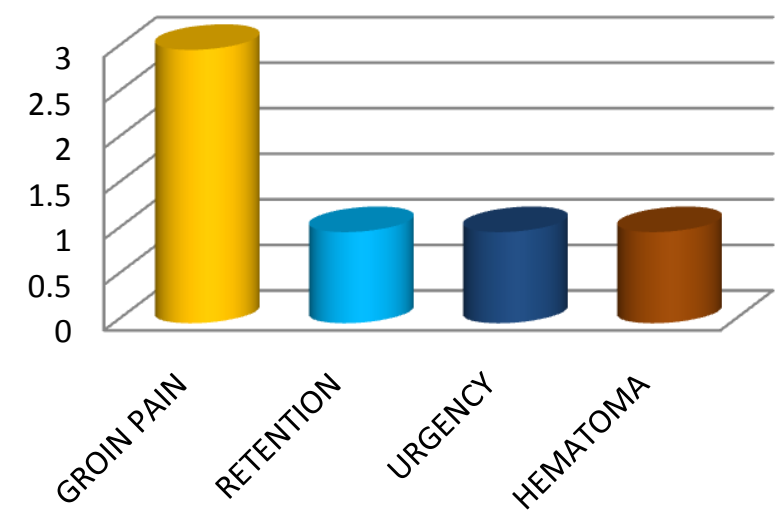

GROIN PAIN

RETENTION

- URGENCY

- HEMATOMA 
Other serious postoperative complication like vaginal /urethral erosion, urinary tract infection, fistula, etc was not noted in the study

Subjective outcome :

\begin{tabular}{|l|l|}
\hline Subjective satisfaction & Number of patient (\%) \\
\hline Very satisfied & 21 \\
\hline Satisfied & 4 \\
\hline Not satisfied & \\
\hline
\end{tabular}

The rate of satisfaction of the inside out transobturator approach was assessed during follow up. 21 patients were very much satisfied with the procedure and 4 patients were satisfied with the procedure Follow up

\begin{tabular}{|l|l|l|}
\hline Follow Up & Preop & Postop \\
\hline Peak Flow Rate (M1/S) & $29.36+2.65$ & $26.65+2.12$ \\
\hline Post Void Residual Urine (Ml) & $21.2 \pm 12.01$ & $15.23 \pm 6.01$ \\
\hline
\end{tabular}

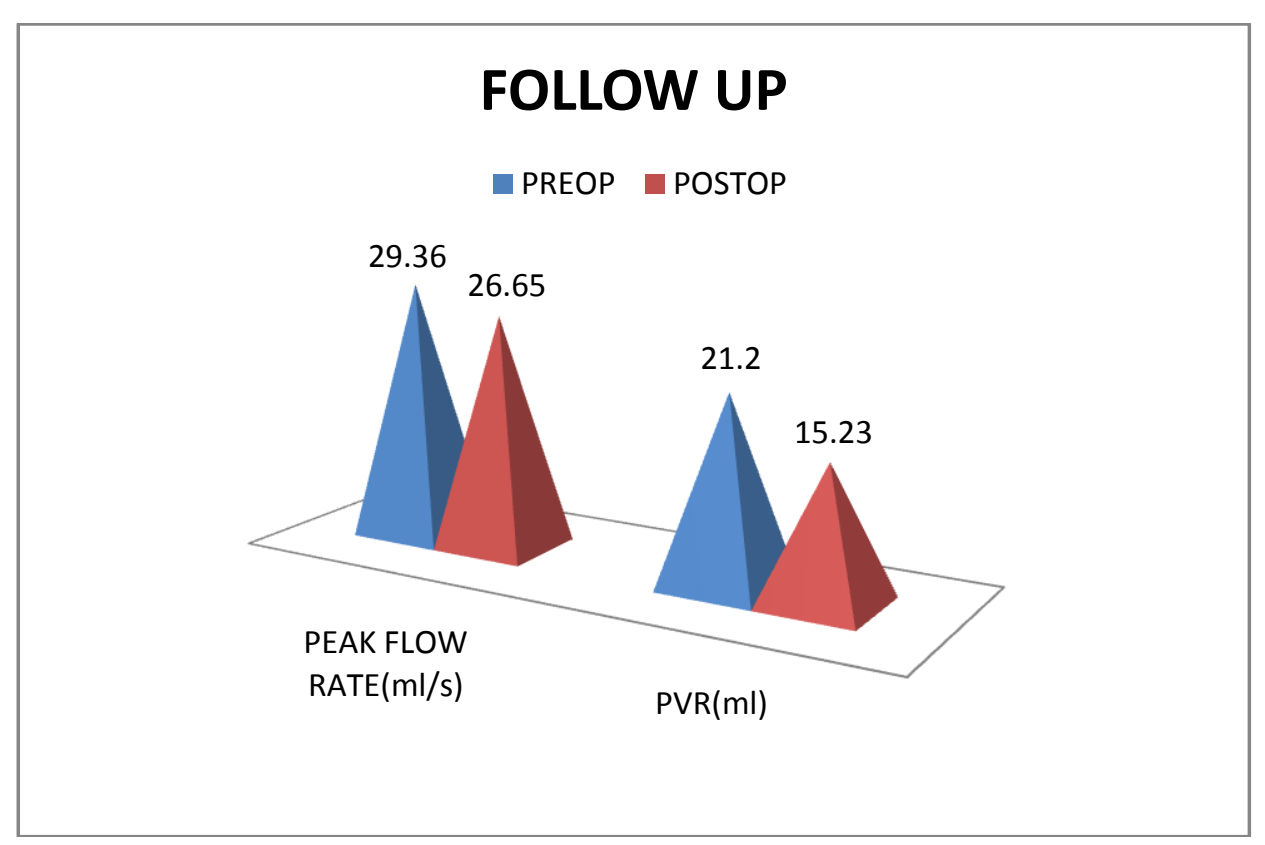

At 6 months follow up ,postoperative assessment of peak flow rate and the residual urine was done. The mean peak flow rate during the follow up was $26.65 \pm 2.12$, the mean post void residual urine during the follow up was $15.23 \pm 6.01$

\section{I-qol(quality of life ):}

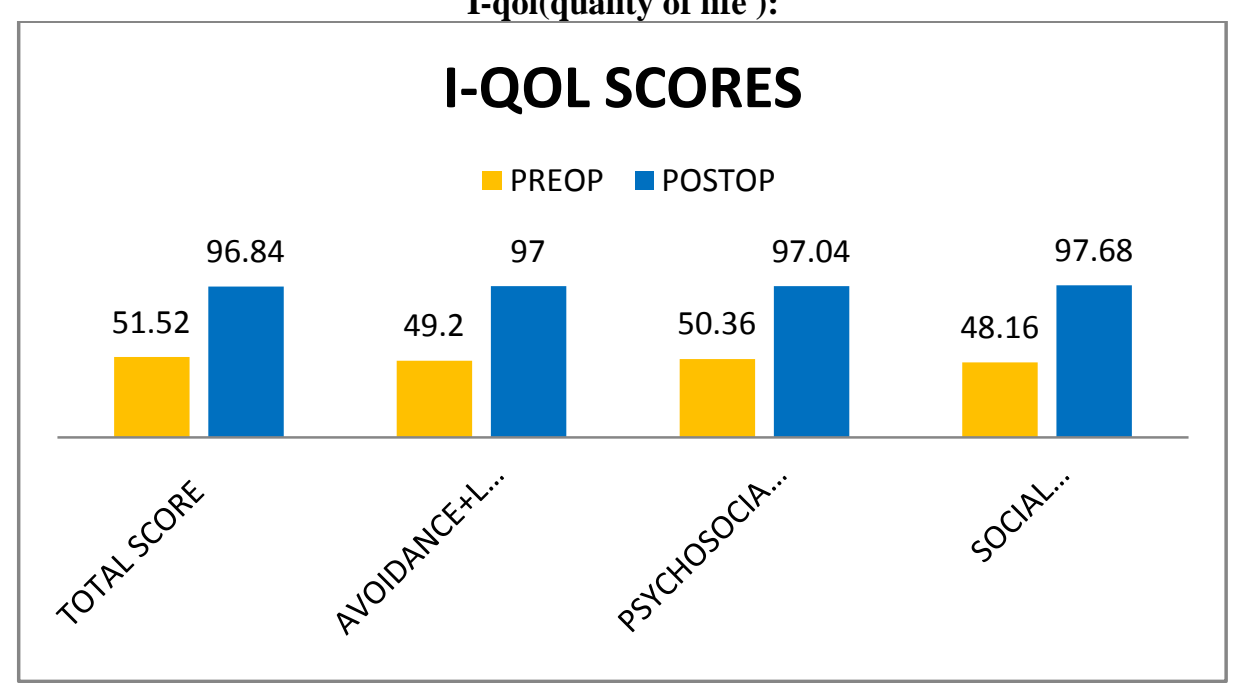




\begin{tabular}{|l|l|l|}
\hline I-QOL SCORES & $\begin{array}{l}\text { Preop } \\
\left(\text { mean }^{+S D}\right)\end{array}$ & $\begin{array}{l}\text { Postop } \\
(\text { mean }+ \text { SD) }\end{array}$ \\
\hline Total & $51.52 \pm+5.49$ & $96.84 \pm+1.43$ \\
\hline Avoidance + limiting behaviour & $49.2 \pm 5.52$ & $97 \pm 1.58$ \\
\hline Psychosocial impacts & $50.36 \pm 6.76$ & $97.04+1.54$ \\
\hline Social embarassment & $48.16 \pm 5.19$ & $97.68+1.97$ \\
\hline
\end{tabular}

All the patients in this study were evaluated using international quality of life questionnaires and the scores were converted to 0 to 100 scale. Scoring was obtained both preoperatively and postoperatively during the follow up.

\section{Discussion}

Stress urinary incontinence is defined as involuntary leakage of urine on effort or exertion,or sneezing or coughing ${ }^{1}$ in the absence of bladder contraction. The tension free vaginal tape procedure described by ulmsten has revolutioned the treatment of female stress urinary incontinence. These tapes have proved their long term efficacy ${ }^{4}$. The risk of lower urinary tract injury or other visceral injury,major blood vessels and nerves ${ }^{5}$.

Spinosa and Dubuis $(2005)^{6}$ followed up 117 patients who underwent inside out transobturator approach for 16.3 months, and the complete and partial subjective cure rates were found as $92.3 \%$ (n:108) and $4.2 \%$ (n:5),respectively.Overall , four patients stated that their condition did not change.In another study that 120 patients were followed up for one year,80\% patients reported that they were completed dry and $12 \%$ reportd that they had recovered almost totally. The initial reports of this inside out approach are encouraging suggesting a similar efficacy with no reported adverse events.Long term data demonstrating sustained efficacy of the transobturator approach has been demonstrated by various clinical studies.

Stress Urinary Incontinence was more commonly seen in younger women in this our study that is comparable to prevalence seen in other clinical studies. The higher level of physical activity seen in younger women than that of older women could be the reason. The average age of the patients was 42.08 years, whereas in a study conducted by swift and ostergard,average age was 59.8 years $^{7}$. The mean parity,the number of children women had in our study was 2.52. Te data collected indicated that the women with 2 children had more stress urinryincontinence, but the fact that almost half of the study population had only two chidren must be taken into consideration ${ }^{8}$. In our study stress urinary incontinence was equal amongst premenopausal women $(52 \%)$ and postmenopausal women $(48 \%)$ similar to the results by Fultz et $\mathrm{al}^{9}$.

Patients with vaginal delivery were found to have a higher association with stress urinary incontinence.As shown in present work, women who had vaginal deliveries more likely to develop stress urinary incontinence than patients who had caesarean section.In a prospective study by in 344 nulliparous women it has shown that vaginal delivery has 18 times increased risk of urinary incontinence in a year when compared to caesarean delivery $^{8}$. In this study $12 \%$ of patients had undergone abdominal hysterectomy and $8 \%$ vaginal hysterectomy compared to $25.4 \%$ and $9.6 \%$ respectively quoted by Bidmead et al ${ }^{10}$.

The present study shows that of women with stress incontinence had 4\%, 68\%, 28\% grade 1,2,3 respectively while teleman et al reported that only $20 \%$ had occasional episode of incontinence and $80 \%$ were incontinent all the time ${ }^{11}$. The mean procedural time was 36 minutes. This was similar to mean operative time of transvaginal tape as reported by abouassaly et $\mathrm{al}^{12}$. The present study has demonstrated that no patients had signs and symptoms of vaginal, urethral, or bladder injury or erosion; or persistent pain during 6 month follow up period. This similar to prospective study by De leval et $\mathrm{al}^{13}$. The present study showed an objective cure rate of $92 \%$ and there was no failure of the procedure. On subjective assessment $84 \%$ of patients were very much satisfied with the procedure and $16 \%$ were satisfied during the follow up. De Neval ${ }^{14}$ in his study of inside out transobturator approach among 108 patients with more than 6 month follow up, 98 were cured (90.7\%), 4 improved $(3.7 \%)$ and 6 failed $(5.6 \%)$.

\section{Conclusion}

The inside out transobturator approach (TVT-O) is an effective and safe technique for the treatment of female stress urinary incontinence. The anatomical and functional mechanism of continence is restored with this minimally invasive approach. The position of the transobturator tape is similar to that of the natural hammock supporting the urethra, respects the orientation of the muscle fibres better than the tension free transvaginal tape operation, and the dissection is less extensive, making tape migration less likely to occur. The para-urethral subvaginal dissection is less extensive with the inside-out route and the learning curve of this approach appears to be quicker.

There are several proven advantage concerning the feasibility of the inside out transobturator technique compared to the transvaginal tape procedure. The short duration of the operation; the low risk of urethral and bladder lesion, making cystoscopy redundant; the absence of risk of bowel lesion; the low risk of haemorrhage. 
Initial and long term results appear to suggest a cure rate similar to that of the transvaginal tape procedure and outside in transobturator approach with decreased incidence of complications.

On conclusion, the inside-out transobturator technique is simple, quick, and safe. It allows the accurate passage of the tape with minimal dissection, protection of the urethra and avoiding the pelvis. There have been no reported urethra or bladder injuries and no bowel or neurological complications. Post-operative continence rates are similar to the transvaginal tape procedure on short-term follow -up. In the future more randomized studies are necessary comparing the various midurethral slings and to further establish efficacy and safety of inside out transobturator vaginal tape.

\section{References}

[1]. Abrams P, Cardozo L, Fall M, Griffiths D, Rosier P, Ulmsten U, Van KP, Victor A, Wein A.The Standardisation Of Terminology In Lower Urinary Tract Function:Report From The Standardisation Sub-Committee Of The International Continence Society . Urology2003;61:37-49

[2]. Singh Abha, Agrawal Priti, Sachdev Nanakra. Incidence And Epidemiology Of Urinary Incontinence In Women: J Obstet Gynecol India Vol.57, No.2: March/April 2007 Pg 155-157

[3]. Isabelle Kaelin-Gambirasio. "Complications Associated With Transobturator Sling Procedures:Analysis Of 233 Consecutive Cases With A 27 Months Follow-Up", BMC Women S Health ,2009

[4]. Francois Haab. “Tension-Free Vaginal Tape:Why An Unusual Concept Is So Successful:”, Current Opinion In Urology , May 2001

[5]. Jorgensen L, Lose G, Andersen JT. One Hour Pad -Weighing Test For Objective Assessment Of Female Urinary Incontinence.Obstet Gynecol 1987;69:39-42.

[6]. Spinosa JP, Dubuis PY. Suburethral Sling Inserted By The Transobturator Route In The Treatment Of Female Stress Urinary Incontinence: Preliminary Results In 117 Cases.Eur J Obstet Gynecol Reprod Biol.2005;123:212-7

[7]. Swift SE, Ostergard DR. Evaluation Of Current Urodynamic Testing Methods In The Diagnosis Of Genuine Stress Incontinence.Obstet Gynecol 1995;86:85-91.

[8]. Tubaro,A.(2001).Risk Factors For Urinary Incontinence In Women.Current Opinion In Urology, 11(1),110-111

[9]. Fultz NH, Herzog AR. Epidemiology Of Urinary Symptoms In The Geriatric Population:Urol Clin North Am 1996;23:1-10

[10]. Bidmead J, Cardozo L, Mclellan A et al. A Comparison Of The Objective And Subjective Outcomes Of Colposuspension For Stress Incontinence In Women.BJOG 2001,108:408-13.

[11]. Teleman PM, Lidfeldt J, Nerband C Et Al. Overactive Bladder: Prevalence, Risk Factors And Relation To Stress Incontinence In Middle Aged Women.BJOG 2004;11:600-4.

[12]. Abouassaly R, Steinberg JR, Lemieux M,Marios C, Gilchrist LI,Bourque J-L, Tu LM, Corcos J. Complication Of Tension -free vaginal tape surgery: A Multi-Institutional Review.BJU INT.2004;94:110-3.

[13]. Bruno Deval. The Midurethral tapes, Vaginal Surgery For Incontinence And Prolapsed , 2006.

[14]. De Leval J.Novel surgical technique for the treatment of female stress urinary incontinence: Transobturator vaginal tape "inside-out" Eur Urol.2003;44:724-30 